\title{
Health determinants of nutritional status in community-dwelling older population: the VERISAÚDE study
}

\author{
Ana Maseda' ', Sarai Gómez-Caamaño', Laura Lorenzo-López'1, Rocío López-López' \\ Clara Diego-Diez ${ }^{1}$, Verónica Sanluís-Martínez ${ }^{1}$, Vanessa Valdiglesias ${ }^{2}$ and \\ José C Millán-Calenti ${ }^{1, *}$ \\ 'Gerontology Research Group, Department of Medicine, Faculty of Health Sciences, Universidade da Coruña, \\ Campus de Oza, E-15071 A Coruña, Spain: ${ }^{2}$ DICOMOSA Group, Department of Psychology, Area of \\ Psychobiology, Edificio de Servicios Centrales de Investigación, Universidade da Coruña, A Coruña, Spain
}

Submitted 28 September 2015: Final revision received 11 February 2016: Accepted 16 February 2016: First published online 15 March 2016

\begin{abstract}
Objective: Malnutrition is a common and relevant syndrome in elderly people due to its influence on quality of life. The main aim of the present study was to identify health determinants of malnutrition or risk of malnutrition.

Design: Cross-sectional study collecting information on sociodemographic and health factors (co-morbidity, cognitive or affective problems, prescription medication use, frailty status, self-rated health) as determinants of nutritional status, assessed by the short form of the Mini Nutritional Assessment.

Setting: Forty-three senior centres from Galicia (north-western Spain) participated to recruit participants.

Subjects: A representative community-dwelling sample of 749 elderly people aged $\geq 65$ years.

Results: Of the total participants, $14.3 \%$ were malnourished/at risk of malnutrition. Presence of overweight or obesity, depressive symptoms, polypharmacy (use of five or more prescription medications), presence of pre-frailty or frailty status and poor selfrated health showed the strongest relationship to malnutrition/risk of malnutrition. This model predicted $86.0 \%$ of the cases correctly. The best determinants for women were polypharmacy and poor self-rated health, reaching $82.8 \%$ of cases of malnourishment/risk of malnutrition predicted correctly. In men, the main determinants were overweight or obesity, depressive symptomatology and polypharmacy, with $89.8 \%$ of cases of malnourishmen/risk of malnutrition predicted correctly.

Conclusions: Screening for nutritional status and its determinant factors should be included as part of comprehensive assessments to ensure an early screening of malnutrition and to propose possible intervention strategies that would be important for both elderly people and the health-care system.
\end{abstract}

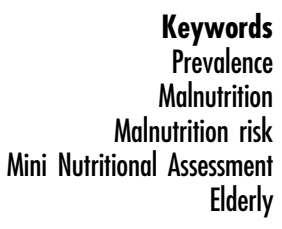

Malnutrition is a frequent syndrome in the elderly. It refers to faulty or inadequate nutritional status, undernourishment characterized by insufficient dietary intake, poor appetite, muscle wasting and weight loss ${ }^{(1)}$.

Malnutrition prevalence varies from $10 \%$ to $85 \%$ in different older age groups around the world due to the different assessment methods used ${ }^{(2)}$. A combined database $^{(3)}$ from all five continents including 4507 people reported a mean prevalence of $22 \cdot 8 \%$, with considerable differences among settings (rehabilitation, 50.5\%; hospital, $38.7 \%$; nursing home, $13.8 \%$; community, $5.8 \%$ ). In this combined database, the 'at risk' group had a mean prevalence of $46.2 \%$. In Spain, a prevalence of malnutrition among the elderly living at home of $12.5 \%$ was reported and $57.5 \%$ for those who were at risk ${ }^{(4)}$.
Nutritional status or nutritional risk screening should be incorporated in comprehensive assessments of the elderly population ${ }^{(5)}$. Age-associated physiological and psychological alterations, functional or cognitive impairment and socio-economic aspects are considered among the main determinants of malnutrition ${ }^{(6)}$, being associated with multiple risk factors ${ }^{(7-9)}$ : female sex, age more than 85 years, low socio-economic level and health status (higher number of co-morbidities or polypharmacy). Regarding co-morbidity, the presence of chronic diseases, such as depression or cognitive impairment, has been related to increased risk of malnutrition ${ }^{(7,10)}$. Additionally, a loss of weight was observed among hospitalized depressed elderly people ${ }^{(11)}$. Furthermore, the effects of drug therapy may have physical manifestations such as 
anorexia or malabsorption of nutrients ${ }^{(12)}$. Most of the studies on polypharmacy and nutritional status concluded that use of a high number of prescription medications was associated with worse outcomes in the Mini Nutritional Assessment (MNA) $)^{(13)}$.

Nutritional deficit, with a significant effect on quality of life, is also a clear determinant of frailty in the elderly. Frail institutionalized or hospitalized elders ${ }^{(14)}$, as well as frail people living in the community ${ }^{(15)}$, have a greater risk of malnutrition.

This health problem is linked to a high risk of morbidity/mortality, longer hospitalizations, along with more frequent readmissions, premature nursing home placements and decreased survival time ${ }^{(1,16)}$. Therefore, early screening aimed to identify potential risk factors for conducting a preventive intervention is necessary.

To our knowledge, although the determinants of malnutrition have been previously investigated, research has not considered multiple health factors with a possible joint effect providing a joint likelihood for poor nutritional status in a large population study. Besides, most previous studies have involved frail or institutionalized elderly, but not healthy elders as main targets for early screening and prevention.

Based on the above, the aim of the present study was to determine the prevalence of malnutrition or risk of malnutrition in a representative community-dwelling elderly population and to examine the association between nutritional status and variables referred to the person, specifically sociodemographic and health factors (co-morbidity, cognitive or affective problems, prescription medication use, frailty status and self-rated health) that affect their quality of life.

\section{Materials and methods}

\section{Selection and description of participants}

Data used were from baseline assessments of the VERISAÚDE (Effectiveness of the Comprehensive Gerontological Assessment and longitudinal follow-up in the healthy ageing promotion) project, which is a large longitudinal study (in the present study, we are using the cross-sectional data) covering a sample of 749 communitydwelling elderly people representative of the Galician population (north-western Spain), aged $\geq 65$ years, living at their home and attending senior centres. Older adults were recruited from forty-three local senior centres. They were invited to participate in the project in different ways and through multiple sources. Associations for the elderly in Galicia were asked to issue an announcement of the study in their centres, by using flyers and word of mouth, so that people who were interested in participating could register. The participants were involved on a voluntary basis and were recruited by representatives of the associations involved in the project. The distribution of the sample by age and sex was similar to that of the entire Galician elderly population, according to the municipal register of the 2011 National Health Survey ${ }^{(17)}$. The level of confidence was $95 \%$, accuracy $\pm 4 \%$ and estimation of data losses $20 \%$. From October 2013 through March 2014, a comprehensive gerontological assessment was conducted.

The inclusion criteria for the participants were as follows: (i) being $\geq 65$ years of age; (ii) be actively enrolled in a Galician association or senior centre; and (iii) willingness to sign the informed consent form. The exclusion criterion for the sample was inability to perform the comprehensive gerontological assessment.

\section{Variables and instruments}

The instruments were administered by a multidisciplinary team of professionals with experience in gerontological assessment (clinical psychologists, nurses, occupational therapists, social workers) and were trained to unify criteria.

\section{Sociodemographic factors}

Information on age, sex and educational level was selfreported. Educational level was categorized into three levels according to years of formal education: $\leq 8$ years, 9-17 years and $\geq 18$ years.

\section{Health aspects}

Nutritional status

The Mini-Nutritional Assessment-Short Form (MNA-SF) ${ }^{(18)}$ is made up of six questions extracted from the full MNA questionnaire $^{(19)}$ : (i) appetite loss or eating problem; (ii) recent weight loss; (iii) mobility; (iv) acute disease or psychological stress; (v) neuropsychological problems (dementia or depression); and (vi) BMI. The MNA-SF has been identified, in a study including 22007 elders, as a suitable screening tool to detect malnourished elders and those at risk for malnutrition, correlating strongly with the full MNA version $(r=0 \cdot 85)^{(20)}$. The Spanish version of the MNA-SF downloaded from the MNA website was used in the present study ${ }^{(21)}$. The total score of the MNA-SF screening test ranges from 0 to a maximum score of 14 points. Those receiving $\leq 11$ points were classified as malnourished or at risk of malnutrition, whereas well-nourished individuals had a score of $\geq 12$ points. Two comparison groups were established in the present study: low MNA-SF score $(\leq 11$ points) $v$. normal MNA-SF score ( $\geq 12$ points), following the dichotomization made by other authors with the MNA (normal nutritional status v. malnutrition/risk) ${ }^{(22,23)}$.

\section{BMI categorization}

The research staff measured weight and height according to standardized protocols. BMI was estimated by dividing weight (kilograms) by the square of height (in metres). A clothing adjustment of approximately $0.8 \mathrm{~kg}$ for women and $1.2 \mathrm{~kg}$ for men was made ${ }^{(24)}$. According to the WHO criteria ${ }^{(25)}$, patients were categorized as not 
overweight if $\mathrm{BMI}<25.0 \mathrm{~kg} / \mathrm{m}^{2}$ and as overweight or obese if $\mathrm{BMI} \geq 25 \cdot 0 \mathrm{~kg} / \mathrm{m}^{2}$.

\section{Co-morbidity}

For all patients, we calculated the value of the Charlson Comorbidity Index (CCI $)^{(26)}$. All nineteen chronic conditions assessed in the survey were given a CCI weight (from 1 to 6) taking into account both the number and seriousness of the co-morbid disease, which ranged from 0 to 37 points. For each patient, a CCI-aged adjusted score was computed, coding co-morbid diseases as $0=$ absent and $1=$ present.

\section{Cognitive and affective assessment}

Global cognitive status was assessed by qualified clinical psychologists using the Spanish version of the Mini-Mental State Examination (MMSE) ${ }^{(27)}$, which examines five areas of cognitive function: (i) orientation to time and place; (ii) short-term memory; (iii) attention; (iv) visual spatial skills; and (v) language and praxis. MMSE scores, ranging from 0 to 30, were adjusted for age and level of education, and participants were considered as cognitively impaired if they scored $\leq 24$ points ${ }^{(28)}$.

Depressive symptoms were also assessed by a psychologist, using the short form of the Geriatric Depression Scale (GDS-SF) ${ }^{(29)}$, a fifteen-item scale specifically developed for screening depressive symptoms in elderly populations. We specifically administered a Spanish-validated version of the test adapted for patients aged $\geq 65$ years $^{(30)}$, which recommends using a cut-off of $\geq 5$ points to consider the existence of probable clinical depression.

\section{Prescription medication use}

The participants were asked to present their drug history (prescribed medications by their general practitioner). Each medication name and current clinical diagnosis were noted. Anatomical Therapeutic Chemical (ATC) classification was used to categorize medications ${ }^{(31)}$. Polypharmacy has been defined as the concomitant use of five or more different prescription medications ${ }^{(32)}$.

\section{Frailty status}

The frailty status of each participant was determined according to the five criteria proposed by Fried et al. ${ }^{(33)}$. In brief, these criteria are the following. (i) Unintentional weight loss (i.e. not due to dieting or exercise): at least $4.5 \mathrm{~kg}$ in the past year. (ii) Self-reported exhaustion: identified by two questions from the modified ten-item Center for Epidemiological Studies-Depression (CES-D) scale $^{(34)}$ in its Spanish version ${ }^{(35)}$. (iii) Weakness: grip strength in the lowest $20 \%$ at baseline, adjusted for sex and BMI. (iv) Slow walking speed: the slowest $20 \%$ at baseline, based on time to walk $4.57 \mathrm{~m}$ (15 ft), adjusting for sex and standing height. (v) Low physical activity: the lowest $20 \%$ at baseline, based on a weighted score of kilocalories expended per week, calculated according to the Spanish validation of the Minnesota Leisure Time Activity (MLTA) questionnaire ${ }^{(36)}$, according to each participant's report, and adjusting for sex. Participants with $\geq 3$ positive criteria were defined as frail, with 1-2 positive criteria as pre-frail, and participants without positive criteria as non-frail.

\section{Self-rated bealth}

Self-rated health was assessed with a single question: 'In general, would you say your health is excellent, good, fair, or poor?' ${ }^{\text {(37). }}$.

\section{Statistical analysis}

Characteristics of the sample were analysed where the quantitative variables were expressed as mean and standard deviation and the qualitative variables as an absolute value and percentage. The normality of the data was tested using the Kolmogorov-Smirnov test, which rejected the assumption of normality. Between-group comparisons were made using the Mann-Whitney $U$ test. The $\chi^{2}$ test was used to test categorical variables and the correlation among quantitative or ordinal variables and the MNA-SF score by the calculation of Spearman's $r$. In order to determine which variables modified a dichotomous dependent variable (MNA-SF categories: well-nourished (normal score, $\geq 12$ points) $v$. malnourished/at risk of malnutrition ( $\leq 11$ points)), a multiple logistic regression analysis (forward stepwise likelihood ratio) was conducted using that dichotomous variable as dependent variable and all the other variables introduced in the model as covariables (sex, age categories, educational level, BMI $\geq 25 \mathrm{~kg} / \mathrm{m}^{2}$, co-morbidity, presence of cognitive impairment, depressive symptoms, frailty status, self-rated health). Categorical variables with more than two values were converted to dummy variables for inclusion in the multivariate models. Odds ratios and 95\% confidence intervals were calculated for each covariate included in the model. The percentage correctly predicted (with a cut-off value of 0.5 for the estimated probability) in the classification table was calculated to evaluate the fit of the final regression model. A $P$ value of $<0.05$ was taken to define statistical significance. The data analysis was conducted using the statistical software package IBM SPSS Statistics Version 21.0.

The manuscript was written according to the STrengthening the Reporting of OBservational studies in Epidemiology (STROBE) statement ${ }^{(38,39)}$.

\section{Results}

The mean age of the sample was $75 \cdot 76$ (SD 7.2) years. Significant differences $(P=0 \cdot 010)$ by sex (Table 1$)$ were found, but no statistical differences between both groups (well-nourished (normal score, $\geq 12$ points) $v$. malnourished/ at risk of malnutrition (low score, $\leq 11$ points)) in the mean 
Table 1 Characteristics according to nutritional status (MNA-SF), well-nourished (normal score, $\geq 12$ points) $v$. malnourished/at risk of malnutrition (low score, $\leq 11$ points), of community-dwelling elderly people $(n+49)$ aged $\geq 65$ years, Galicia, north-western Spain, October 2013-March 2014 (VERISAUDE study)

\begin{tabular}{|c|c|c|c|c|c|c|c|}
\hline & \multicolumn{2}{|c|}{$\begin{array}{l}\text { Normal MNA-SF score } \\
(\text { ( } 642)\end{array}$} & \multicolumn{2}{|c|}{$\begin{array}{l}\text { Low MNA-SF score } \\
(n 107)\end{array}$} & \multirow[b]{2}{*}{$P$ value } & \multicolumn{2}{|c|}{$\begin{array}{l}\text { Total } \\
(n 749)\end{array}$} \\
\hline & $n$ or Mean & $\%$ or SD & $n$ or Mean & $\%$ or SD & & $n$ or Mean & $\%$ or SD \\
\hline Sex, $n$ and \%* & & & & & $0.010 \dagger$ & & \\
\hline Men & 265 & 41.3 & 30 & $28 \cdot 0$ & & 295 & 39.4 \\
\hline Women & 377 & $58 \cdot 7$ & 77 & $72 \cdot 0$ & & 454 & $60 \cdot 6$ \\
\hline Age (years), mean and SD & $75 \cdot 7$ & $7 \cdot 1$ & $75 \cdot 9$ & $7 \cdot 3$ & $0.779 \ddagger$ & $75 \cdot 76$ & $7 \cdot 2$ \\
\hline Education (years), $n$ and $\%$ & & & & & $0.412 \dagger$ & & \\
\hline$\leq 8$ & 381 & $59 \cdot 3$ & 70 & 65.4 & & 451 & $60 \cdot 2$ \\
\hline$\overline{9}-17$ & 155 & $24 \cdot 1$ & 24 & $22 \cdot 4$ & & 179 & 23.9 \\
\hline$\geq 18$ & 106 & $16 \cdot 5$ & 13 & $12 \cdot 1$ & & 119 & $15 \cdot 9$ \\
\hline Total MNA-SF score, mean and SD** & 13.5 & 0.8 & $10 \cdot 1$ & 1.2 & $<0.001 \ddagger$ & 13.04 & 1.5 \\
\hline $\mathrm{BMI}\left(\mathrm{kg} / \mathrm{m}^{2}\right)$, mean and SD & $29 \cdot 0$ & $4 \cdot 1$ & 28.7 & $5 \cdot 6$ & $0.272 \ddagger$ & 28.96 & 4.3 \\
\hline Age-adjusted $\mathrm{CCl}$ score, mean and SD & 4.4 & 1.4 & 4.6 & 1.4 & $0.114 \ddagger$ & 4.40 & 1.4 \\
\hline Total MMSE score, mean and SD & $28 \cdot 3$ & $2 \cdot 3$ & $28 \cdot 1$ & $2 \cdot 3$ & $0.170 \ddagger$ & $28 \cdot 30$ & $2 \cdot 3$ \\
\hline Total GDS-SF score, mean and SD** & 1.3 & $1 \cdot 8$ & $2 \cdot 6$ & $2 \cdot 9$ & $<0.001 \ddagger$ & 1.51 & $2 \cdot 1$ \\
\hline Number of prescription medications, mean and SD ${ }^{\star *}$ & 4.5 & $3 \cdot 2$ & $6 \cdot 5$ & 3.5 & $<0.001 \ddagger$ & 4.80 & $3 \cdot 3$ \\
\hline Frailty phenotype, $n$ and $\% * *$ & & & & & $<0.001 \dagger$ & & \\
\hline No frailty & 169 & $26 \cdot 3$ & 14 & $13 \cdot 1$ & & 183 & $24 \cdot 4$ \\
\hline Pre-frailty & 458 & 71.3 & 80 & 74.8 & & 538 & 71.8 \\
\hline Frailty & 15 & $2 \cdot 3$ & 13 & $12 \cdot 1$ & & 28 & 3.7 \\
\hline Self-rated health, $n$ and $\% * \star$ & & & & & $<0.001 \dagger$ & & \\
\hline Excellent & 150 & $23 \cdot 4$ & 15 & $14 \cdot 0$ & & 165 & $22 \cdot 1$ \\
\hline Good & 359 & $56 \cdot 0$ & 61 & $57 \cdot 0$ & & 420 & $56 \cdot 1$ \\
\hline Fair & 121 & 18.9 & 21 & $19 \cdot 6$ & & 142 & $19 \cdot 0$ \\
\hline Poor & 11 & 1.7 & 10 & $9 \cdot 3$ & & 21 & $2 \cdot 8$ \\
\hline
\end{tabular}

MNA-SF, Mini-Nutritional Assessment-Short Form; CCl, Charlson Comorbidity Index; MMSE, Mini-Mental State Examination; GDS-SF, Global Deterioration Scale-Short Form.

${ }^{\star} P<0.05,{ }^{\star \star} P<0.01$.

t $\chi^{2}$ test.

$\ddagger$ Mann-Whitney $U$ test.

age or educational level. For nutritional status, 642 participants $(85.7 \%)$ were well-nourished, 101 participants $(13.5 \%)$ were at risk of malnutrition and six (0.8\%) were malnourished. The combined prevalence for the malnourished/at risk of malnutrition group was $14.3 \%$.

GDS-SF scores were significantly different between groups (well-nourished: 1.32 (SD 1.84); malnourished/at risk of malnutrition: 2.64 (SD 2.91); only $8.1 \%$ of participants showed depressive symptomatology). Additionally, well-nourished individuals used a significantly lower number of prescription medications than those who were malnourished/at risk of malnutrition (4.52 (SD 3.17) v. 6.51 (SD 3.52)). Statistically significant differences were found in the different categories of the frailty phenotype $(P<0 \cdot 001)$ and self-rated health $(P<0.001)$ between groups.

In search of the relationship between MNA-SF score and the different sociodemographic aspects and indicators of health (Table 2), a correlation between MNA-SF score and age $(r=-0.088 ; P=0.016)$ and BMI $(r=0.100 ; P=0 \cdot 006)$ was found. Older individuals with higher BMI had lower MNA-SF scores (higher presence of malnourishment/risk of malnutrition).

Significant negative correlations were also observed with age-adjusted CCI score $(r=-0.076 ; \quad P=0.038)$, GDS-SF score $(r=-0.228 ; P<0.001)$, number of prescription medications $(r=-0.208 ; \quad P<0 \cdot 001)$, frailty score $(r=-0.193$; $P<0.001)$ and self-rated health $(r=-0.140 ; \quad P<0.001)$.
Table 2 Associations between all quantitative or ordinal variables listed in Table 1 and the MNA-SF score among community-dwelling elderly people $(n 749)$ aged $\geq 65$ years, Galicia, north-western Spain, October 2013-March 2014 (VERISAÚDE study)

\begin{tabular}{lc}
\hline & MNA-SF-score \\
\cline { 2 - 2 } & $r$ \\
\hline Age (years) & $-0.088^{\star}$ \\
Education (years) & $0 \cdot 042$ \\
BMI $\left(\mathrm{kg} / \mathrm{m}^{2}\right)$ & $0 \cdot 100^{\star *}$ \\
Age-adjusted CCl score & $-0.076^{*}$ \\
Total MMSE score & 0.069 \\
Total GDS-SF score & $-0.228^{\star *}$ \\
Number of prescription medications & $-0.208^{\star *}$ \\
Frailty total score & $-0.193^{\star *}$ \\
Self-rated health & $-0.140^{\star *}$
\end{tabular}

MNA-SF, Mini-Nutritional Assessment-Short Form; $r$, Spearman's rho; $\mathrm{CCl}$, Charlson Comorbidity Index; MMSE, Mini-Mental State Examination; GDS-SF, Global Deterioration Scale-Short Form.

${ }^{\star} P<0.05,{ }^{\star *} P<0.01$.

Frailty or pre-frailty, presence of higher co-morbidity, depressive symptoms, use of a higher number of prescription medications and poor self-rated health presented lower MNA-SF scores (higher presence of malnourished/risk of malnutrition).

Finally, Table 3 shows the results of a logistic regression model, where five determinants significantly associated with malnutrition/risk of malnutrition are presented. For the total population, the five main determinants were BMI 


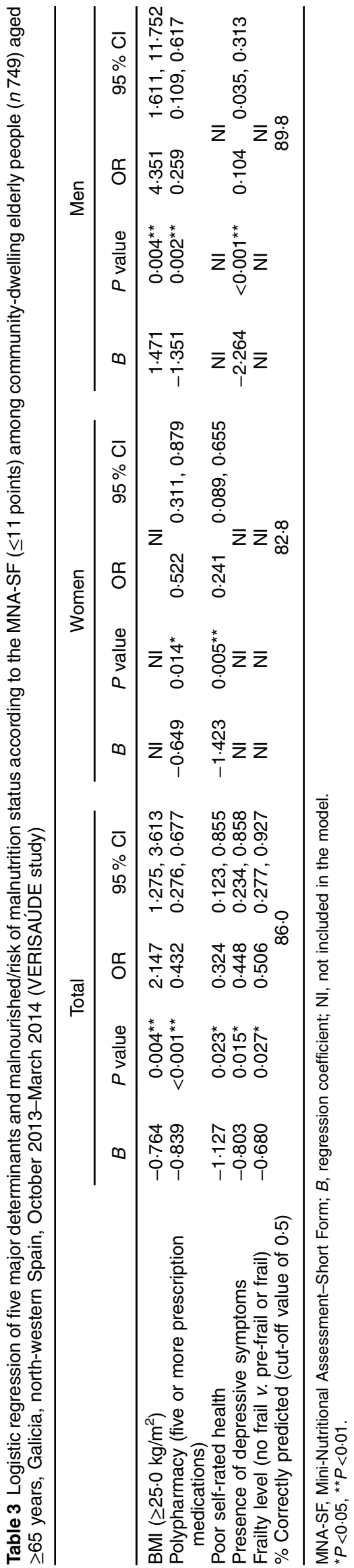

( $\geq 25.0 \mathrm{~kg} / \mathrm{m}^{2}$, presence of overweight or obesity), presence of depressive symptoms, number of prescription medications (five or more, polypharmacy), frailty level (pre-frail or frail) and poor self-rated health. The combination of having all the factors increased the risk of reporting malnutrition/risk of malnutrition, with a correct prediction of $86.0 \%$. Moreover, the regression model identified different determinants according to sex. The best determinants for women were also polypharmacy and poor self-rated health, reaching a correct prediction of $82.8 \%$ of those malnourished/risk of malnutrition. In men, the main determinants of malnutrition/risk of malnutrition were overweight or obesity, presence of depressive symptoms and polypharmacy; when considered together, the correct classification of the cases reporting malnutrition/risk of malnutrition was $89 \cdot 8 \%$.

\section{Discussion}

A low prevalence of malnutrition or risk of malnutrition was observed in the present study according to MNA-SF score, but we must consider that we conducted our study in healthy elders, living at home independently and with a potentially good health status. Other studies ${ }^{(40,41)}$ involving community-dwelling healthy elderly people have also found similar data for malnutrition $(0 \%$ and $0.5 \%$, respectively) and risk of malnutrition (12.6\% and $9.5 \%$, respectively). Research done in a rural population of India ${ }^{(42)}$ showed higher prevalences of malnutrition (14\%) and risk of malnutrition (49\%) among free-living elderly than those observed in our study. This difference may be explained by the different place of living. The present study included elderly people residing in both rural and urban areas, and a previous large study done in $\operatorname{Iran}^{(43)}$ showed higher malnutrition rates in rural than in urban participants.

Among the sociodemographic aspects investigated in the current study, sex was significantly related to malnourishment/risk of malnutrition in bivariate analysis, with lower MNA-SF scores being observed in women, although sex did not enter the multivariate model. Numerous studies have pointed out that female sex is associated with malnutrition and malnutrition risk $^{(44-47)}$. In our study, there was a significant although very weak negative correlation between age and MNA-SF score (older participants had poorer nutritional status) that was not reported in bivariate and regression analyses among the well-nourished as compared with those who were malnourished or at risk of malnutrition. These findings are in accordance with data reported in a Spanish crosssectional study including 22007 elders, where lower scores were obtained in the oldest subjects ${ }^{(20)}$. The fact that age determines malnutrition was also found in older Chinese adults ${ }^{(48)}$, although some previous researchers did not find such a correlation or association ${ }^{(42,49)}$. Most individuals in our study $(60 \cdot 2 \%)$ had a very low 
educational level; however, education was not related to poor nutritional status. Contrary to our results, other authors have mentioned that lower levels of education are associated with malnutrition ${ }^{(46,48,50,51)}$. These data are considering an association between poverty, low levels of education and malnutrition; in fact, lower levels of education are very frequent in low-income people, with greater difficulties in covering nutritional needs.

After the comprehensive gerontological assessment and the multivariate regression model analysis carried out in the present study, associated factors for malnutrition or the risk of malnutrition were a low BMI, depressive symptoms, polypharmacy, presence of pre-frailty or frailty status and poor self-rated health. Other authors ${ }^{(9)}$ who investigated the relationship between socio-economic indicators as well as physical and mental health characteristics and nutritional status found that community-dwelling elderly people suffering from poor financial condition, those with multiple chronic diseases, those reporting chronic pain or presenting mental disorders were at high risk of malnutrition. Unfortunately, no information about the combined effect of all these factors to predict the likelihood of malnutrition/risk of malnutrition was provided.

The association of health factors and poor nutritional status found in our study is in concordance with other researchers. BMI correlated positively with MNA-SF score (as expected; since BMI is also a part of the MNA-SF it is not advisable to use it as the only parameter to detect malnutrition $^{(10)}$ ) but bivariate and logistic regression analyses showed that malnourishment/risk of malnutrition was not associated with BMI. Low MNA score was associated with low BMI and increased weight loss ${ }^{(20,23)}$.

Age-adjusted CCI scores correlated negatively with MNA-SF scores but bivariate and logistic regression analyses showed that malnutrition was not associated with co-morbidity, as described earlier ${ }^{(52)}$; thus, nutritional status is closely related to the accumulation of geriatric conditions, at least in dependant elderly people without acute illness $^{(53)}$. On the other hand, the number of chronic medical conditions has been found to be one of the best predictors of nutritional status ${ }^{(48)}$. Among these geriatric conditions, dementia is itself a risk factor for malnutrition $^{(52)}$. In the present study, however, no association was found between MMSE score and malnutrition or risk of malnutrition. It could be that most of the people attending senior centres are healthy elders without cognitive impairment (only $6.5 \%$ of the participants were found to have cognitive impairment). Nevertheless, the majority of studies have shown that patients affected by cognitive impairment (lower MMSE scores) are characterized by a poor nutritional status ${ }^{(54-57)}$. Generally, these studies involved elderly patients with dementia and/or were carried out in an institutionalized setting.

Further, in the ageing population, depression is a frequent syndrome that has shown association with nutritional status in several settings ${ }^{(49,58-63)}$. The current study found the same significant association. Various researchers have demonstrated a positive association between depression and loss of appetite or weight loss; therefore, poor nutritional status could be a factor contributing to depression and apathy in elders ${ }^{(49,58-63)}$. Nevertheless, new research is needed to determine whether malnourishment or risk of malnutrition is regarded as a consequence of depressive symptomatology or, inversely, if malnourished people have a greater risk of being depressed.

Polypharmacy (five or more prescription medications) was also identified as a marker of poor nutritional status in our study. Other findings indicate that polypharmacy is strongly associated with low MNA scores and a higher number of prescription medications determines the decline in MNA scores ${ }^{(13,16,64,65)}$. The effects of polypharmacy on nutritional status are estimated from the fact that problems with nutrition occur mainly in elderly patients, who are also more frequently subject to polypharmacy. However, it is unclear if a worsened nutritional status may influence the process of a pharmacological treatment or, inversely, if polypharmacy may influence a limited food intake that would increase malnutrition ${ }^{(65)}$.

Frailty was also found more often in our study participants who were malnourished or at risk of malnutrition. Frailty is a geriatric condition determined by Fried et al.'s five criteria that assess, among other factors, unintentional weight loss and weakness adjusted by BMI, items that are already implying an existing close association with malnutrition. Our result may be compared with a previous Spanish study which found a significant association between the five frailty criteria and the categories of MNA, and that the largest proportion of frail subjects were at risk of malnutrition ${ }^{(15)}$. Additionally, 90\% of malnourished elderly patients were either pre-frail or frail, and about $36 \%$ or $57 \%$ of the frail people were malnourished or at risk of malnutrition ${ }^{(14,66)}$. These authors also found that the prevalence of malnutrition was six times higher in frail older adults compared with robust individuals.

Lastly, self-perceived health provides a measurement for monitoring the health status of the elderly and its effect on their quality of life and well-being. In our representative sample, only $2.8 \%$ perceived poor health. This can be compared with other studies which found that being at nutritional risk had a negative impact on older people's perceived health ${ }^{(2,63,67)}$. Lower risk of undernutrition using MNA-SF scores could predict perceived good health ${ }^{(67)}$.

\section{Strengths and limitations}

An important strength of the present study is the multiple assessment set of potential determinants (both sociodemographic and health ones) that are included in the analysis to examine their association with the presence of malnourishment or risk of malnutrition in a large representative sample. However, there are several limitations to be mentioned such as the selection of our sample study 
from senior centres and the inclusion of healthy elders that could reduce the prevalence rates of malnutrition or risk of malnutrition.

Likewise, several studies ${ }^{(68,69)}$ have reported higher prevalence rates for malnutrition in the presence of dysphagia. Although dysphagia is a geriatric syndrome and a predictor of malnutrition, it was not considered in our gerontological assessment. Besides, cross-sectional designs do not allow establishing causality, so that future longitudinal data are needed.

\section{Conclusions}

The present research provides insight into the factors that could be associated with the presence of malnutrition or risk of malnutrition. We conclude that sex was the only sociodemographic factor associated with nutritional status in our community-dwelling older people. Health factors that demonstrated association were depressive symptomatology, polypharmacy, frailty and poor self-rated health. Our study revealed, in a multivariate analysis, that low BMI, depressive symptoms, polypharmacy (five or more prescription medications), presence of pre-frailty or frailty status and poor self-rated health remained as determinants of malnourishment and risk of malnutrition. Screening for nutritional status and these determinant factors should be included as part of comprehensive assessments to ensure an early screening of malnutrition and to propose possible intervention strategies that would be important for both elderly people and the health-care system.

\section{Acknowledgements}

Acknowledgements: The authors sincerely thank the staff and elderly users of the forty-three senior centres who contributed to this study. Financial support: This work was supported by the Xunta de Galicia project EM 2012/ 100: 'VERISAÚDE project: Effectiveness of the Comprehensive Gerontological Assessment and longitudinal follow-up in the healthy ageing promotion'. Xunta de Galicia had no role in the design, analysis or writing of this article. Conflict of interest: None. Authorship: A.M., S.G.-C. and J.C.M.-C. contributed with the conception and design of the study along with the critical revision of the manuscript before the final submission. S.G.-C., L.L.-L., R.L.-L., V.S-.M. and C.D.-D. contributed with the acquisition of data. A.M. contributed with the analysis and interpretation of data along with the drafting of the manuscript. All the authors revised the final version of the manuscript and approved it to be submitted. Ethics of human subject participation: This study was conducted according to the guidelines laid down in the Declaration of Helsinki and all procedure involving human subjects/patients were approved by the Ethics Committee of the University of
A Coruña. Written informed consent was obtained for all subjects.

\section{References}

1. Chen CC, Schilling LS \& Lyder CH (2001) A concept analysis of malnutrition in the elderly. J Adv Nurs 36, 131-142.

2. Margetts BM, Thompson RL, Elia M et al. (2003) Prevalence of risk of undernutrition is associated with poor health status in older people in the UK. Eur J Clin Nutr $\mathbf{5 7}$, 69-74.

3. Kaiser MJ, Bauer JM, Rämsch C et al. (2010) Frequency of malnutrition in older adults: a multinational perspective using the mini nutritional assessment. J Am Geriatr Soc 8, $1734-1738$.

4. De La Montana J \& Miguez M (2011) Suitability of the shortform Mini Nutritional Assessment in free-living elderly people in the northwest of Spain. J Nutr Health Aging 15, 187-191.

5. Salvà A \& Pera G (2001) Nutrition and ageing. Public Health Nutr 4, 1375-1378.

6. Valls T \& Mach N (2012) Risk of malnutrition in people older than 75 years. Med Clin (Barc) 139, 157-160.

7. Ferdous T, Kabir ZN, Wahlin A et al. (2009) The multidimensional background of malnutrition among rural older individuals in Bangladesh - a challenge for the Millennium Development Goal. Public Health Nutr 12, 2270-2278.

8. Cabrera MAS, Mesas AE, Garcia AR et al. (2007) Malnutrition and depression among community-dwelling elderly people. J Am Med Dir Assoc 8, 582-584.

9. Boulos C, Salameh P \& Barberger-Gateau P (2014) Factors associated with poor nutritional status among community dwelling Lebanese elderly subjects living in rural areas: results of the AMEL study. J Nutr Health Aging 18, 488-494.

10. Rodríguez-Tadeo A, Wall-Medrano A, Gaytan-Vidaña ME et al. (2012) Malnutrition risk factors among the elderly from the US-Mexico border: the 'one thousand' study. J Nutr Health Aging 16, 426-431.

11. German L, Feldblum I, Bilenko N et al. (2008) Depressive symptoms and risk for malnutrition among hospitalized elderly people. J Nutr Health Aging 12, 313-318.

12. Cowan DT, Roberts JD, Fitzpatrick JM et al. (2004) Nutritional status of older people in long term care settings: current status and future directions. Int J Nurs Stud $\mathbf{4 1}$, 225-237.

13. Jyrkkä J, Mursu J, Enlund H et al. (2012) Polypharmacy and nutritional status in elderly people. Curr Opin Clin Nutr Metab Care 15, 1-6.

14. Dorner TE, Luger E, Tschinderle J et al. (2014) Association between nutritional status (MNA ${ }^{\circledR}-\mathrm{SF}$ ) and frailty (SHARE-FI) in acute hospitalised elderly patients. J Nutr Health Aging 18, 264-269.

15. Jürschik P, Botigué T, Nuin C et al. (2014) Association between Mini Nutritional Assessment and the Fried frailty index in older people living in the community. Med Clin (Barc) 143, 191-195.

16. Schilp J, Wijnhoven HAH, Deeg DJH et al. (2011) Early determinants for the development of undernutrition in an older general population: Longitudinal Aging Study Amsterdam. Br J Nutr 106, 708-717.

17. Spanish Statistical Office (2011) Population Demographic Censuses. Municipal Register 2011. http://www.ine.es/jaxi/ tabla.do (accessed September 2012).

18. Kaiser MJ, Bauer JM, Ramsch C et al. (2009) Validation of the Mini Nutritional Assessment short-form (MNA-SF): a practical tool for identification of nutritional status. J Nutr Health Aging 13, 782-788.

19. Guigoz Y, Vellas BJ \& Garry PJ (1994) Mini Nutritional Assessment: a practical assessment tool for grading the 
nutritional state of elderly patients. Facts Res Gerontol Suppl. 2, 15-59.

20. Cuervo M, García A, Ansorena D et al. (2009) Nutritional assessment interpretation on 22007 Spanish communitydwelling elders through the Mini Nutritional Assessment test. Public Health Nutr 12, 82-90.

21. Nestlé Nutrition Institute (2009) Guía para rellenar el formulario Mini Nutritional Assessment $\left(\mathrm{MNA}^{\circledR}{ }^{\circledR}\right)$. http://www. mna-elderly.com/mna_forms.html (accessed March 2015).

22. Gil-Montoya JA, Ponce G, Sánchez Lara I et al. (2013) Association of the oral health impact profile with malnutrition risk in Spanish elders. Arch Gerontol Geriatr 57, 398-402.

23. Saka B, Kaya O, Ozturk GB et al. (2010) Malnutrition in the elderly and its relationship with other geriatric syndromes. Clin Nutr 29, 745-748.

24. Whigham LD, Schoeller DA, Johnson LK et al. (2013) Effect of clothing weight on body weight. Int J Obes (Lond) $\mathbf{3 7}$, 160-161.

25. World Health Organization (2006) BMI Classifications. http://www.who.int/bmi/index.jsp?introPage=intro_3.html (accessed March 2015)

26. Charlson ME, Pompei P, Ales KL et al. (1987) A new method of classifying prognostic comorbidity in longitudinal studies: development and validation. J Chronic Dis $\mathbf{4 0}$, 373-383.

27. Folstein MF, Folstein SE \& McHugh PR (1975) 'Mini-Mental State'. A practical method for grading the cognitive state of patients for the clinician. J Psychiatr Res 12, 189-198.

28. Blesa R, Pujol M, Aguilar M et al. (2001) NORMAlisation of Cognitive and Functional Instruments for DEMentia: clinical validity of the 'mini-mental state' for Spanish speaking communities. Neuropsychologia 39, 1150-1157.

29. Sheikh JL \& Yesavage JA (1986) Geriatric Depression Scale (GDS). Recent evidence and development of a shorter version. Clin Gerontol 5, 165-172.

30. Martínez de la Iglesia J, Onís Vilches MC, Dueñas Herrero R et al. (2002) The Spanish version of the Yesavage abbreviated questionnaire (GDS) to screen depressive dysfunctions in patients older than 65 years. MEDIFAM 12, 620-630.

31. WHO Collaborating Center for Drug Statistics Methodology (2013) Guidelines for ATC Classification and DDD Assignment 2013. Oslo: WHO Collaborating Centre for Drug Statistics Methodology.

32. Gnjidic D, Hilmer SN, Blyth SM et al. (2012) Polypharmacy cutoff and outcomes: five or more medicines were used to identify community-dwelling older men at risk of different adverse outcomes. J Clin Epidemiol 65, 989-995.

33. Fried LP, Tangen CM, Walston J et al. (2001) Frailty in older adults: evidence for a phenotype. J Gerontol A Biol Sci Med Sci 56, M146-M156.

34. Radloff LS (1977) The CES-D scale: a self-report depression scale for research in the general population. Appl Psychol Meas 1, 385-401.

35. Ruiz-Grosso P, Loret de Mola C, Vega-Dienstmaier JM et al. (2012) Validation of the Spanish Center for Epidemiological Studies Depression and Zung Self-Rating Depression Scales: a comparative validation study. PLoS One 7, e 45413.

36. Ruiz Comellas A, Pera G, Baena Díez JM et al. (2012) Validation of a Spanish Short Version of the Minnesota Leisure Time Physical Activity Questionnaire (VREM). Rev Esp Salud Publica 86, 495-508.

37. Kanagae M, Abe Y, Honda S et al. (2006) Determinants of self-rated health among community-dwelling women aged 40 years and over in Japan. Tohoku J Exp Med 210 $11-19$.

38. von Elm E, Altman DG, Egger $M$ et al. (2008) The Strengthening the Reporting of Observational Studies in Epidemiology (STROBE) statement: guidelines for reporting observational studies. J Clin Epidemiol 61, 344-349.
39. Vandenbroucke JP, von Elm E, Altman DG et al. (2007) Strengthening the Reporting of Observational Studies in Epidemiology (STROBE): explanation and elaboration. Epidemiology 18, 805-835.

40. Iizaka S, Tadaka E \& Sanada H (2008) Comprehensive assessment of nutritional status and associated factors in the healthy, community-dwelling elderly. Geriatr Gerontol Int 8, 24-31.

41. Salvà A, Bolibar I \& Bleda MJ (1999) MNA in clinical practice. In Mini Nutritional Assessment (MNA): Research and Practice in the Elderly, pp. 35-46 [B Vellas, PJ Garry and Y Guigoz, editors]. Basel: Karger.

42. Vedantam A, Subramanian V, Rao NV et al. (2010) Malnutrition in free-living elderly in rural south India: prevalence and risk factors. Public Health Nutr 13, 1328-1332.

43. Alibadi M, Kimiagar M, Ghayour-Mobarhan M et al. (2008) Prevalence of malnutrition in free living elderly people in Iran: a cross-sectional study. Asia Pac J Clin Nutr 17, 285-289.

44. Cankurtaran M, Saka B, Sahin S et al. (2013) Turkish nursing homes and care homes nutritional status assessment project (THN-malnutrition). Eur Geriatr Med 4, 323-329.

45. Aliabadi M, Kimiagar M, Ghayour-Mobarhan M et al. (2008) Prevalence of malnutrition in free living elderly people in Iran: a cross-sectional study. Asia Pac J Clin Nutr 17, 285-289.

46. Kabir ZN, Ferdous T, Cederholm $\mathrm{T}$ et al. (2006) Mini Nutritional Assessment of rural elderly people in Bangladesh: the impact of demographic, socio-economic and health factors. Public Health Nutr 9, 968-974.

47. Boulos C, Salameh P \& Barberger-Gateau P (2013) The AMEL study, a cross sectional population-based survey on aging and malnutrition in 1200 elderly Lebanese living in rural settings: protocol and sample characteristics. $B M C$ Public Health 13, 573.

48. Ham Y, Li S \& Zheng Y (2009) Predictors of nutritional status among community-dwelling older adults in Wuhan, China. Public Health Nutr 12, 1189-1196.

49. Ahmadi SM, Mohammadi MR, Mostafavi SA et al. (2013) Dependence of the geriatric depression on nutritional status and anthropometric indices in elderly population. Iran J Psychiatry 8, 92-96.

50. Donini LM, Scardella P, Piombo L et al. (2013) Malnutrition in elderly: social and economic determinants. J Nutr Health Aging 17, 9-15.

51. Timpini A, Facchi E, Cossi S et al. (2011) Self-reported socioeconomic status, social, physical and leisure activities and risk for malnutrition in late life: a cross-sectional populationbased study. J Nutr Health Aging 15, 233-238.

52. Malara A, Sgrò G, Caruso C et al. (2014) Relationship between cognitive impairment and nutritional assessment on functional status in Calabrian long-term-care. Clin Interv Aging 9, 105-110.

53. Hirose T, Hasegawa J, Izawa S et al. (2014) Accumulation of geriatric conditions is associated with poor nutritional status in dependent older people living in the community and in nursing homes. Geriatr Gerontol Int 14, 198-205.

54. El Zoghbi M, Boulos C, Amal AH et al. (2013) Association between cognitive function and nutritional status in elderly: a cross-sectional study in three institutions of Beirut-Lebanon. Geriatr Mental Health Care 1, 73-81.

55. Nykänen I, Lönnroos E, Kautiainen H et al. (2013) Nutritional screening in a population-based cohort of community-dwelling older people. Eur J Public Health 23, 405-409.

56. Droogsma E, van Asselt DZB, Schölzel-Dorenbos CJM et al. (2013) Nutritional status of community-dwelling elderly with newly diagnosed Alzheimer's disease: prevalence of malnutrition and the relation of various factors to nutritional status. J Nutr Health Aging 17, 606-610. 
57. Roque M, Salvà A \& Vellas B (2013) Malnutrition in community-dwelling adults with dementia (NUTRIALZ TRIAL). J Nutr Health Aging 17, 295-299.

58. Feldblum I, German L, Castel H et al. (2007) Characteristics of undernourished older medical patients and the identification of predictors for undernutrition status. Nutr J 6, 37.

59. Yoshimura K, Yamada M, Kajiwara Y et al. (2013) Relationship between depression and risk of malnutrition among community-dwelling young-old and old-old elderly people. Aging Ment Health 17, 456-460.

60. Kvamme JM, Gronli O, Florholmen J et al. (2011) Risk of malnutrition is associated with mental health symptoms in community living elderly men and women: the Tromsø Study. BMC Psychiatry 11, 112.

61. Kaburagi T, Hirasawa R, Yoshino H et al. (2011) Nutritional status is strongly correlated with grip strength and depression in community-living elderly Japanese. Public Health Nutr 14, 1893-1899.

62. Mokhber N, Majdi MR, Ali-Abadi M et al. (2011) Association between malnutrition and depression in elderly people in Razavi Khorasan: a population based-study in Iran. Iran J Public Health 40, 67-74.

63. Johansson $\mathrm{Y}$, Bachrach-Lindström $\mathrm{M}$, Carstensen $\mathrm{J}$ et al. (2009) Malnutrition in a home-living older population: prevalence, incidence and risk factors. A prospective study. J Clin Nurs 18, 1354-1364.

64. Jyrkkä J, Enlund H, Lavikainen P et al. (2011) Association of polypharmacy with nutritional status, functional ability and cognitive capacity over a three-year period in an elderly population. Pharmacoepidemiol Drug Saf 20, 514-522.

65. Zadak Z, Hyspler R, Ticha A et al. (2013) Polypharmacy and malnutrition. Curr Opin Clin Nutr Metab Care 16, 50-55.

66. Bollwein J, Volkert D, Diekmann R et al. (2013) Nutritional status according to the mini nutritional assessment $\left(\mathrm{MNA}^{\circledR}\right)$ and frailty in community dwelling older persons: a close relationship. J Nutr Health Aging 17, 351-356.

67. Söderhamn U, Flateland S, Jessen L et al. (2011) Perceived health and risk of undernutrition: a comparison of different nutritional screening results in older patients. J Clin Nurs 20, 2162-2171.

68. Serra-Prat M, Palomera M, Gomez C et al. (2012) Oropharyngeal dysphagia as a risk factor for malnutrition and lower respiratory tract infection in independently living older persons: a population-based prospective study. Age Ageing 41, 376-381.

69. Takeuchi K, Aida J, Ito K et al. (2014) Nutritional status and dysphagia risk among community-dwelling frail older adults. J Nutr Health Aging 18, 352-357. 